\title{
Fabrication of biomimetic superhydrophobic steel surface under an oxygen rich
} environment

\author{
Liang Yin ${ }^{1}$, Haifeng Zhang ${ }^{1,2}$, Yuyang $\mathrm{Li}^{1}$, Yang Wang ${ }^{1}$, Ruimin Zhang ${ }^{1}$, Weiping \\ Chen ${ }^{1}$, Xiaowei Liu ${ }^{1,2}$
}

${ }^{1}$ MEMS Center, Harbin Institute of Technology, Harbin, 150001, China

${ }^{2}$ Key Laboratory of Micro-Systems and Micro-Structures Manufacturing, Ministry of Education, Harbin, 150001, China

* Tel: +86 451 86413451; Fax: +86 451 86413441; e-mail: zhanghf@hit.edu.cn

\begin{abstract}
:
A novel and facile approach was proposed to fabricate superhydrophobic surface with similar micro-and nanostructures of lotus leaf on the steel foil. The acidic solution was used to grow $\mathrm{Fe}_{3} \mathrm{O}_{4}$ nanosheet films consisted of hydrochloric acid and potassium chloride under an $\mathrm{O}_{2}$ rich environment. The as-prepared superhydrophobic steel surfaces had water CA (contact angle) of $166 \pm 2^{\circ}$. The water SA (sliding angle) was less than $2^{\circ}$. In order to estimate the drag reduction property of the as-prepared surface, the experimental setup of the liquid-solid friction drag was proposed. The drag reduction ratio for superhydrophobic surface was $61.3 \%$ compare with untreated surface at a flow velocity of $1.66 \mathrm{~m} \mathrm{~s}^{-1}$.
\end{abstract}

\section{Introduction}


Wettability is a very important aspect of materials and governed by both the surface chemical composition and geometric structure [1-9]. Since, superhydrophobicity of lotus leaves was revealed by Barthlott and Neinhuis, superhydrophobic surfaces have attracted extensive attentions in both academia and industry. Many researches on superhydrophobic surfaces have been inspired by mimicking natural models such as the superhydrophobic lotus leaf which possesses dual scale micro-/nanostructures along with a waxy coating [10]. The wetting or dewetting behavior of solid materials is often determined by both surface roughness and chemical composition. The hydrophobicity can be greatly enhanced by means of increasing surface roughness and lowering surface free energy [11-13]. Therefore, artificial superhydrophobic surfaces have been manufactured mainly by two methodologies: creating micro-/nanostructures on hydrophobic substrates, or chemically modifying a micro-/nanostructured surface with materials of low surface free energy. In recent years, a variety of methods had been developed to mimic surface for the fabrication of many artificial superhydrophobic surfaces [14-18].

As an important engineering material, steel is widely used in many industrial fields, including petrochemical, construction, maritime and aviation industries. The fabrication of superhydrophobic steel surface has attracted much attention largely because of their practical or potential engineering applications. Many techniques have been proposed to generate superhydrophobic surfaces on the steel, such as solution immersion, nano coating, electrochemical deposition, and laser fabrication [19, 20]. Zhao presented a simple method for fabricating stainless steel-based superhydrophobic surfaces using a femtosecond laser [21]. Sethi reported the synthesis of superhydrophobic coatings on the 
steel using carbon nanotube (CNT) mesh structures [22]. However, many of these methods subject to certain limitations, such as special equipment, expensive material, complex process, long period, and poor durability. As a result, it is highly desirable to develop a simple, commercial, time-saving, and reliable method to fabricate stable superhydrophobic surface. Nonetheless, chemical etching is an inexpensive and easily controlled approach compared with the other methods [23,24]. However, the electrochemical machining and chemical etching methods require the acid corrosive procedure, while sulfuric acid, chlorhydric acid, nitric acid, and hydrofluoric acid are often used. These acids need high concentration to fabricate the superhydrophobic surface, and hazard to the environment and the health of the operator. Herein, we present a novel method to fabricate a superhydrophobic surface on a steel sheet via chemical etching and oxidation technology in acidic solution with low concentration. The acidic solution used in the growth process consisted of hydrochloric acid and potassium chloride under an $\mathrm{O}_{2}$ rich environment. The steel substrate was grown the $\mathrm{Fe}_{3} \mathrm{O}_{4}$ film with nanoflower-like structure. The as-prepared surface after modified with fluorinated silane shows superhydrophobic property with a static water CAs of $166 \pm 2^{\circ}$. The sliding angle is lower than $2^{\circ}$. Moreover, the superhydrophobic surface possesses long-term stability and chemical stability.

\section{Experimental}

\subsection{Materials and methods}

All chemicals were analytical grade reagents and used as received without further purification. A typical experiment procedure was as follows: steel foils with thickness of $0.3 \mathrm{~mm}$ and dimension of $2 \times 2 \mathrm{~cm}^{2}$ were polished with $800 \#, 1200 \#$, and 1700\# 
sandpaper in turn, and then cleaned ultrasonically with acetone and deionized water to remove grease, respectively. The acidic solution used in the growth process consisted of hydrochloric acid $(\mathrm{HCl})$ and $0.2 \mathrm{M}$ potassium chloride $(\mathrm{KCl})$ [25]. The $\mathrm{pH}$ value of the solution was adjusted to be around 3 as indicated by a $\mathrm{pH}$ paper. $200 \mathrm{~mL}$ of the solution was loaded into a glass beaker and then heated to around $70{ }^{\circ} \mathrm{C}$ by a hotplate. A steel foil sample was then immersed into the solution. The steel foil thus provided the raw Fe material needed for nanostructure formation of iron-oxide. To expedite the growth and etching of iron-oxide with this technique, we introduced pure oxygen bubbles at the flow rate of $160 \mathrm{sccm}$ to the solution. The chemical oxidation process is similar to other $\mathrm{Fe}_{3} \mathrm{O}_{4}$ nanostructures growth by the conventional hydrothermal technique [26,27]. A magnetic bar rotated at a rate of $120 \mathrm{rpm}$ provided continuous stirring to the solution during the growth processes. After reacting for a certain time, it was picked out and then immersed into $50 \mathrm{~mL}$ of distilled water for about $1 \mathrm{~h}$ before dried in $\mathrm{N}_{2}$ environment. Finally, these samples were immersed in an ethanol solution of fluorinated silane (FAS, $1 \mathrm{H}, 1 \mathrm{H}, 2 \mathrm{H}, 2 \mathrm{H}$-perfluorooctadecyltrichlorosilane) of $0.5 \mathrm{wt} \%$ for $30 \mathrm{~min}$, and then dried in a vacuum oven at $120^{\circ} \mathrm{C}$ for $60 \mathrm{~min}$. The superhydrophobic steel surface was thus obtained.

\subsection{Sample characterization}

The surface morphologies were observed using a field-emission scanning electron microscope (FE-SEM, TESCAN VEGA), and the corresponding element distributions were determined by energy-dispersive X-ray spectroscopy (EDS). The X-ray diffraction (XRD) patterns of the samples were recorded with a Bruker D8 Advance diffractometer equipped with a $\mathrm{Cu} \mathrm{K}_{\alpha}$ radiation source $(\lambda=0.15418 \mathrm{~nm})$. The CAs and SAs of water 
droplets were measured by an optical contact-angle meter system (Data Physics Instrument $\mathrm{GmbH}$, Germany) at ambient temperature. The water $\mathrm{CA}$ and $\mathrm{SA}$ reported were the mean values measured with $5 \mu \mathrm{L}$ of water droplets at five different positions on each test surface. Sliding angle was determined by slowly tilting the sample stage until a $5 \mu \mathrm{L}$ water droplet started moving. The drag reduction efficiency was measured by a self-designed water spraying system.

\section{Results and discussion}

Fig. 1(a) and (c) show the optical photographs of the substrate before and after growth. The shiny Fe surface turns to dark/black color after treatment for 25 min, suggesting the formation of magnetite $\left(\mathrm{Fe}_{3} \mathrm{O}_{4}\right)$ on the $\mathrm{Fe}$ surface [25]. The corresponding SEM images of the Fe substrate and $\mathrm{Fe}_{3} \mathrm{O}_{4}$ nanosheets grown in $70^{\circ} \mathrm{C}$ acidic solution are shown in Fig. 1(c) and (d), respectively. From Fig. 1(b) we can see that prior to chemical etching, the steel surface is relatively smooth. Only several scratches and pits generated by polishing are present on the surfaces. Fig. 1(d) is the SEM image of the resultant nanosheets film on the steel foil, which shows flower-like structure. After chemical etching and oxidation of the steel foils, microprotrusions with the diameters of $2-5 \mu \mathrm{m}$ are distributed across the surface. The inset of Fig. 1(d) is the subsurface image at a higher resolution. The crooked nanosheets with the thickness of 50-60 nm are grown uniformly on the steel surface.

To understand the growth process of the hierarchical structure, the effect of the reaction time on the morphology of the products was studied by SEM observations ( Fig. 2 ). When the reaction time is short ( $5 \mathrm{~min})$, the nanosheets is sparsely covered with only several flower-like microspheres (Fig. 2(a)). From the high-resolution image, it can be seen that the nanoflowers are all made up of curly nanowalls. When the reaction time 
reaches $20 \mathrm{~min}$, more and more nanoflowers are formed and their size grow bigger gradually (Fig.2 (b)). Fig.2 (c) and (d) are the SEM image of the nanosheets film prepared at $70{ }^{\circ} \mathrm{C}$ in the acidic solution for $30 \mathrm{~min}$ and lotus surface, respectively. From Fig. 2(c) we can see that many microprotrusions with the diameter ranging from $2-5 \mu \mathrm{m}$ are evenly distributed on the surface of the etched steel sheet increasing reaction time to 30 min. The surface of a single papilla is rough as shown in the inset of Fig. 2(c), many nanosheets can be observed on the papilla. Fig. 2(c) is greatly similar to lotus surfaces (Fig. 2(d)). A possible procedure for the formation of micro and nanosheets is proposed. When the Fe substrate is immersed in the acidic solution, ferrous ions $\left(\mathrm{Fe}^{2+}\right)$ will pass into solution. Under an oxygen-deficient environment, ferrous hydroxide id formed. Intermediate oxidation products of ferrous hydroxide are a mixture of $\mathrm{Fe}^{3+}$ and $\mathrm{Fe}^{2+}$ ions, also form and grow on the substrate surface. The unstable dark green hydrated magnetite sample transforms to stable black magnetite when immersed in distilled water. The proposed sequence of reactions is [25]:

$$
\begin{gathered}
\mathrm{Fe} \rightarrow \mathrm{Fe}^{2+}+2 e^{-} \\
\mathrm{Fe}^{2+}+2 \mathrm{OH}^{-} \rightarrow \mathrm{Fe}(\mathrm{OH})_{2} \\
6 \mathrm{Fe}(\mathrm{OH})_{2}+\mathrm{O}_{2} \rightarrow 4 \mathrm{H}_{2} \mathrm{O}+2 \mathrm{Fe}_{3} \mathrm{O}_{4} \cdot \mathrm{H}_{2} \mathrm{O} \\
\mathrm{Fe}_{3} \mathrm{O}_{4} \cdot \mathrm{H}_{2} \mathrm{O} \rightarrow \mathrm{H}_{2} \mathrm{O}+\mathrm{Fe}_{3} \mathrm{O}_{4}
\end{gathered}
$$

The corresponding element distributions were determined by energy-dispersive X-ray spectroscopy (EDS). Fig. 3 shows the EDS spectrum of the before and after growth surface, which reveals the presence of Fe, C and $\mathrm{O}$ elements. From Fig. 3(a) we can see that there has $\mathrm{O}$ element on the untreated steel surface. The reason is that the surface of 
untreated steel foil is oxidized in the air. Fig. 3(b) shows the EDS spectrum of the resultant $\mathrm{Fe}_{3} \mathrm{O}_{4}$ Film. The strong peaks for $\mathrm{Fe}$ and $\mathrm{O}$ are observed in the spectrum with the atomic ratio of $1: 1.25$, which is close to the theoretical value $(1: 1.33)$ that of magnetite. To analyze the composition and crystal structures of the iron oxides, the sample was subjected to XRD measurements. Fig. 3(c) shows XRD peaks of as-synthesized sample (dark line). Magnetite is believed to be the major crystalline phase for the synthesized nanosheets as identified by the new diffraction peaks at $30.2^{\circ}, 35.6^{\circ}$, $43.3^{\circ}, 57.3^{\circ}$, and $62.9^{\circ}$. These peaks correspond to five indexed planes (220), (311), (400), (511), and (440), respectively, of magnetite.

The wettability of steel surfaces was evaluated by the water static CA and SA measurements. Fig.4 shows the photos of water droplets on the different samples. Steel foils are hydrophilic materials with native oxidized top layers having water CAs of about $11^{\circ}$ (Fig. 4(a)). After the etching and oxidation, the surface of the steel shows water CAs of approximate $0^{\circ}$ (Fig. 4(b)). After modified the silane regent, the wettability of the steel foil after $(\mathrm{HCl}+0.2 \mathrm{M} \mathrm{KCl}, \mathrm{PH}=3)$ prepared $\mathrm{Fe}_{3} \mathrm{O}_{4}$ films at $70^{\circ} \mathrm{C}$ acidic solution for 25 min under an $\mathrm{O}_{2}$ rich environment is successfully converted from superhydrophility to superhydrophobicity. The average $\mathrm{CA}$ increases from $0^{\circ}$ to $166^{\circ}$ (Fig. 4(c)). It is indicated that the surface roughness and chemical composition are necessary for superhydrophobicity. According the Cassie-Baxter model, as-prepared surfaces have binary structures at both micrometer and nanometer scales, which trap a large amount of air and to minimize the real contact area between surfaces and water droplets. Besides, sliding angle is another important criterion for a superhydrophobic surface [28, 29]. Thus, 
we measure the sliding angle of modified $\mathrm{Fe}_{3} \mathrm{O}_{4}$ nanosheet surface and get a sliding angle less than $2^{\circ}$. We have also characterized the dynamic of the water drop on the superhydrophobic surface. Fig. 5 is snapshot photographs of a $10 \mu \mathrm{L}$ water droplet rolling off of the resultant superhydrophobic surface. It is observed that the water droplet cannot stably sit on the superhydrophobic surface. It rolls off immediately with very little hysteresis, indicating that the water droplet can be effortlessly moved (video. S1, Supplementary material). These above phenomena indicate that a water drop slides very easily on the fabricated lotus-leaf-like superhydrophobic steel surface.

The reaction time in acidic solution has distinct influence on the surface wettability. Fig. 6 shows the change of the water CA on the modified steel surface with the different treatment time in $70^{\circ} \mathrm{C}$ acidic solution under $\mathrm{O}_{2}$ rich environment. It can be found from Fig. 6 that the water contact angle has reached $142 \pm 2^{\circ}$ for the sample that only treated in the acidic solution for $10 \mathrm{~min}$. As the reaction time increased to $15 \mathrm{~min}$, the CA improves to $153 \pm 2^{\circ}$, and the surface reaches superhydrophobicity and possesses low adhesion. When the reaction time is prolonged to $20 \mathrm{~min}$, the contact angle is enhanced to $163 \pm 2^{\circ}$. Furthermore, when reaction time becomes $30 \mathrm{~min}$, the CA of $166 \pm 2^{\circ}$ is the largest and SA is less than $2^{\circ}$. However, the CA slightly decreases with the treatment time lengthen further. The reason that leads to this result can be deduced as follows: the film thickness increase when further increasing the treatment time. The surface has some crack after vacuum drying by heating due to surface stress. The superhydrophobicity is weakened.

The stability and corrosion resistance of the superhydrophobicity surfaces are evaluated in various environments. Fig. 7 displays the relationship between $\mathrm{pH}$ value and water $\mathrm{CA}$ on the superhydrophobic steel surfaces. The as-prepared surfaces also show 
superhydrophobic properties in the $\mathrm{pH}$ range from 1 to 14 , that is to say, the CAs are larger than $150^{\circ}$ not only for water but also for corrosive liquids, such as acidic, basic and some salt aqueous solutions. The water $\mathrm{CA}$ on the superhydrophobic steel surface increases from $152 \pm 2^{\circ}$ to $156 \pm 2^{\circ}$ with the change in $\mathrm{pH}$ from 1 to 2 . At $\mathrm{PH}>3$, the water CAs are larger than $160 \pm 2^{\circ}$. These results are very important for the use of as-prepared superhydrophobic steel foil as engineering materials in the wide $\mathrm{pH}$ range of corrosive liquids. After incubating under an ambient environment for three months, the CA of the as-prepared superhydrophobic surface was still as high as $161 \pm 2 \circ$, indicating good stability of the superhydrophobic surface in air.

As-prepared surface has the characteristic of low adhesion. In order to estimate the drag reduction property, an experimental setup of the liquid/solid friction drag was reported [30]. The drag reduction property of the as-prepared surface was measured for 5 s with the same flow rate. The average values were ultimately selected as the friction drag of the corresponding surface. Moreover, the friction drag was also measured under different flow rates to investigate the influence of the flow rate on the drag reduction performance. As shown in Fig.8, we can see that the superhydrophobic surface has the low friction drag. This phenomenon can be aptly explained by that the magnitude of hydrodynamic slippage which characterizes the anti-drag performance is closely linked to the wettability of a special structured surface. Qualitatively, for the superhydrophobic surface, there is a large but not continuous liquid-air contact layer which prevents the interaction of liquid and solid surface. Thus it is extremely hard for liquid momentum parallel to the interface to transfer, and as a consequence, a long slip length is generated. From the Fig. 8, we can also see that the flow velocity can affect the drag reduction. The 
drag reduction ratio for superhydrophobic surface is $61.3 \%$ compare with untreated surface at a flow velocity of $1.66 \mathrm{~m} \mathrm{~s}^{-1}$. When the flow velocity was about $4.5 \mathrm{~m} \mathrm{~s}^{-1}$, the drag reduction ratio of the superhydrophobic surface reduced to $16.1 \%$. Fig. 9 shows the change of the water CAs after flushing water on a fabricated steel surface. It shows that the CAs have obvious decrease with increasing flow rate. The surface is dried after being flushed water with flow velocity of $4.5 \mathrm{~m} \mathrm{~s}^{-1}$, its superhydrophobicity is recovered from $151 \pm 2^{\circ}$ to $162 \pm 2^{\circ}$. The reason is that higher flow velocities cause faster removal rates

of the surface air layer in flowing water. The disappearance of entrapped gas would cause declining drag reduction because of decreasing slippage. With increasing flow velocity, a rise in drag was observed, which was attributed to the morphology of the surface air layer and its depletion by high shear flow.

\section{Conclusion}

In summary, we have successfully developed a novel avenue to fabricate a highly similar surface structure of lotus leaf on a steel sheet by the chemical etching and oxidation. After modification with fluorinated silane, the lotus-leaf-like steel surface shows superhydrophobic property. The water contact angle and sliding angle of the as-prepared superhydrophobic steel surface are about $166^{\circ}$ and less than $2^{\circ}$, respectively. It also exhibits the non-sticking behavior, long-term storage stability. The as-prepared surfaces also show superhydrophobic properties in the $\mathrm{pH}$ range from 1 to 14 . The drag reduction ratio for superhydrophobic surface is $61.3 \%$ compare with untreated surface at a flow velocity of $1.66 \mathrm{~m} \mathrm{~s}^{-1}$. These properties are favorable for the potential applications of steel materials for drag reduction field. 


\section{Acknowledgements}

The work was supported by National Basic Research Program of China (No.2012CB934100), National Science Foundation of China (No. 61474034), Natural Science Foundation of Heilongjiang Province of China(NO: F201418), the Fundamental Research Funds for the Central Universities (Grant No. HIT.NSRIF.2014040, HIT.NSRIF.2013040).

\section{References}

[1] Y. Chen, B. He, J. Lee, N. A. Patankar, Anisotropy in the wetting of rough surfaces, J. Colloid Interface Sci. 281 (2005) 458-464.

[2] X. Feng, L. Feng, M. Jin, J. Zhai, L. Jiang, Reversible super-hydrophobicity to super-hydrophilicity transition of aligned $\mathrm{ZnO}$ nanorod films, J. Am. Chem. Soc. 126 (2004) 62-63.

[3] Z.G. Guo, W.M. Liu, Biomimic from the superhydrophobic plant leaves in nature: binary structure and unitary structure, Plant Sci. 172 (2007) 1103-1112.

[4] K. Koch, B. Bhushan, Y.C. Jung, W. Barthlott, Fabrication of artificial Lotus leaves and significance of hierarchical structure for superhydrophobicity and low adhesion, Soft Matter. 5 (2009) 1386-1393.

[5] B Bhushan, Y.L. Wang, A Maali, Boundary slip study on hydrophilic, hydrophobic, and superhydrophobic surfaces with dynamic atomic force microscopy, Langmuir. 25 (2009) 8117-8121.

[6] T. Sun, L. Feng, X. Gao, L. Jiang, Bioinspired surfaces with special wettability,Acc. Chem. Res. 38 (2005) 644-652. 
[7] B. Bhushan, K. Koch, Y.C. Jung, Biomimetic hierarchical structure for selfcleaning, Appl. Phys. Lett. 93 (2008) 093101.

[8] F. Zhang, L. Zhao, H. Chen, S. Xu, D. Evans, X. Duan, Corrosion resistance of superhydrophobic layered double hydroxide films on aluminum, Angew. Chem. Int. Ed. 47 (2008) 2500-2503.

[9] J. Genzer, K. Efimenko, Recent developments in superhydrophobic surfaces and their relevance to marine fouling: a review, Biofouling 22 (2006) 339-360.

[10] C. Lee, C.J. Kim, Underwater restoration and retention of gases on superhydrophobic surfaces for drag reduction, Phys. Rev. Lett. 106 (2011) 014502.

[11] Z. Yuan, X. Wang, J. Bin, C. Peng, S. Xing, M. Wang, A novel fabrication of a superhydrophobic surface with highly similar hierarchical structure of the lotus leaf on a copper sheet, Appl. Surf. Sci. 15 (2013) 205-210.

[12] A. Pozzato, S. D. Zilio, G. Fois, D. Vendramin, G. Mistura, M. Belotti, Y. Chen, M. Natali, Superhydrophobic surfaces fabricated by nanoimprint lithography, Microelectron. Eng. 83 (2006) 884-888.

[13] L. Feng, H. Zhang, P. Mao, Y. Wang, Y. Ge, Superhydrophobic alumina surfacebased on stearic acid modification, Appl. Surf. Sci. 257 (2011) 3959-3963.

[14] T. Wu, Y. Pan, L. Li, Study on superhydrophobic hybrids fabricated from mul-tiwalled carbon nanotubes and stearic acid, J. Colloid Interface Sci. 348 (2010) $265-270$.

[15] Y. Yan, N. Gao, W. Barthlott, Mimicking natural superhydrophobic surfaces and grasping the wetting process: a review on recent progress in preparing superhydrophobic surfaces, Adv. Colloid Interface Sci. 169 (2011) 80-105. 
[16] Y. Lee, S.H. Park, K.B. Kim, J.K. Lee, Fabrication of hierarchical structures on a polymer surface to mimic natural superhydrophobic surfaces, Adv. Mater. 19 (2007) 2330-2335

[17] H. Liu, X. Wang, H. Ji, Fabrication of lotus-leaf-like superhydrophobic surfaces via Ni-based nano-composite electro-brush plating, Appl. Surf. Sci. 288 (2014)341-348.

[18] L.J. Liu, J.S. Zhao, Y. Zhang, F. Zhao, Y.B. Zhang, Fabrication of superhydrophobic surface by hierarchical growth of lotus-leaf-like boehmite on aluminum foil, J. Colloid Interface Sci. 358 (2011) 277-283

[19] X.J. Feng, L. Jiang, Design and creation of superwetting/antiwetting surfaces, Adv. Mater. 18 (2006) 3063-3078.

[20] X.J. Liu, Y.M. Liang, F Zhou, W.M. Liu, Extreme wettability and tunable adhesion: biomimicking beyond nature?, Soft Matter. 8 (2012) 2070-2086.

[21] B. Wu, M. Zhou, J. Li, X. Ye, L. Cai, Superhydrophobic surfaces fabricated by microstructuring of stainless steel using a femtosecond laser, Appl. Surf. Sci. 256 (2009) 61-66

[22] S. Sethi, A. Dhinojwala, Superhydrophobic conductive carbon nanotube coatings for steel, Langmuir, 25 (2009) 4311-4313.

[23] L. Li, V. Breedveld, D W. Hess, Creation of superhydrophobic stainless steel surfaces by acid treatments and hydrophobic film deposition, ACS Appl. Mater. Interfaces, 4 (2012) 4549-4556.

[24] N. J. Yu, Y. F. Yu, Y. F. Li, S. P. Song, S. B. Huo, X. Y. Han, Preparation and characterization of super-hydrophobic surfaces on aluminum and stainless steel substrates, Surf. Rev. Lett. 17 (2010) 375-381. 
[25] K.C. Chin, G.L. Chong, C.K. Poh, L.H. Van, C.H. Sow, J. Lin, A. Wee, Large-scale synthesis of $\mathrm{Fe}_{3} \mathrm{O}_{4}$ nanosheets at low temperature, J. Phys. Chem. C. 111 (2007) 9136-9141.

[26] S. Y. Lian, E. Wang, Z. H. Kang, Y. P. Bai, L. Gao, M. Jiang, C. W. Hu, L. Xu, Synthesis of magnetite nanorods and porous hematite nanorods, Solid State Commun. 129 (2004) 485-490.

[27] T. Ishikawa, Y. Kondo, A. Yasukawa, K. Kandori, Formation of magnetite in the presence of ferric oxyhydroxides, Corros. Sci. 40 (1998) 1239-1251.

[28] L. Gao, T.J. McCarthy, Contact angle hysteresis explained, Langmuir 22 (2006) 6234-6237.

[29] B. Balu, V. Breedveld, D.W. Hess, Fabrication of "roll-off" and "sticky" superhydrophobic cellulose surfaces via plasma processing, Langmuir 24 (2008) 4785-4790.

[30] H. F. Zhang, L. Yin, L. Li, S.Y. Shi, Y Wang, X.W. Liu, Wettability and drag reduction of a superhydrophobic aluminum surface, RSC adv. 6 (2016) 14034-14041. 
Fig. 1. Optical photographs taken at two slightly different orientations perpendicular to Fe substrate surface (a) before and (c) after grow for 25 min in acidic solution with introduced oxygen bubbles. ( $b$ and d) corresponding SEM images of the Fe substrate surfaces and $\mathrm{Fe}_{3} \mathrm{O}_{4}$ films. Large area uniform synthesis of $\mathrm{Fe}_{3} \mathrm{O}_{4}$ nanosheets is observed.

Fig. 2. SEM images of the nanosheets film prepared at $70{ }^{\circ} \mathrm{C}$ in the acidic solution for (a) $5 \mathrm{~min}$, (b) $20 \mathrm{~min}$, (c) $30 \mathrm{~min}$, and (d) SEM image of lotus surface

Fig. 3. EDS spectrum of (a) before and (b) after grow nanosheet films for 30min in acidic solution with introduced oxygen bubbles, (c) XRD patterns of the as-prepared surface, the red box represents the diffraction peaks for $\mathrm{Fe}_{3} \mathrm{O}_{4}$.

Fig. 4. Optical photo of water droplets on different morphology surface: (a) untreated steel surface, (b) surface of chemical etching and oxidation, and (c) superhydrophobic steel surface.

Fig. 5. Snapshot photographs of a $10 \mu \mathrm{L}$ water droplet rolling off of the resultant superhydrophobic surface (30 min) (a) $0.5 \mathrm{~s}$, (b) $1 \mathrm{~s}$, (c) $1.5 \mathrm{~s}$, and (d) $2 \mathrm{~s}$.

Fig. 6. Relationship between the water CA of the as-prepared steel foil and the reaction time in $70^{\circ} \mathrm{C}$ acidic solution under $\mathrm{O}_{2}$ rich environment. Samples have been modified by fluorinated silane after chemical etching and oxidation.

Fig. 7. Relationship between the water CA of the as-prepared superhydrophobic steel surfaces and $\mathrm{pH}$ value.

Fig. 8. Friction drag versus the velocity of the water flowing over surfaces

Fig. 9. Graph showing CA measured after flushing water with different flow velocity on the superhydrophobic steel surface. 



Fig.1. Optical photographs taken at two slightly different orientations perpendicular to Fe substrate surface (a) before and (c) after grow for 25 min in acidic solution with introduced oxygen bubbles. ( $b$ and $d$ ) corresponding SEM images of the Fe substrate surfaces and $\mathrm{Fe}_{3} \mathrm{O}_{4}$ films. Large area uniform synthesis of $\mathrm{Fe}_{3} \mathrm{O}_{4}$ nanosheets is observed. 

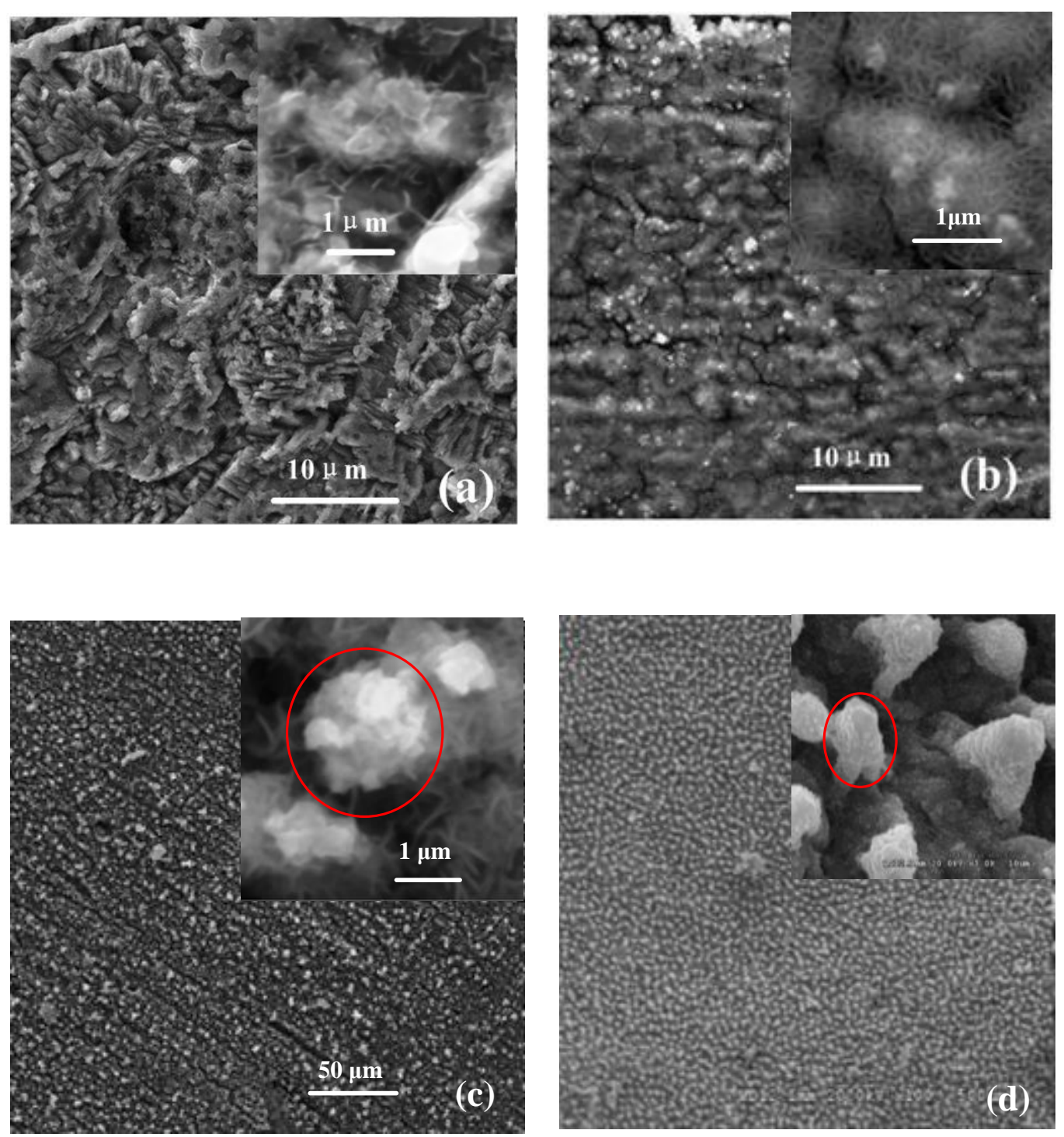

Fig. 2. SEM images of the nanosheets film prepared at $70{ }^{\circ} \mathrm{C}$ in the acidic solution for

(a) $5 \mathrm{~min}$, (b) $20 \mathrm{~min}$, and (c) $30 \mathrm{~min}$,

(d) SEM image of lotus surface[17] 

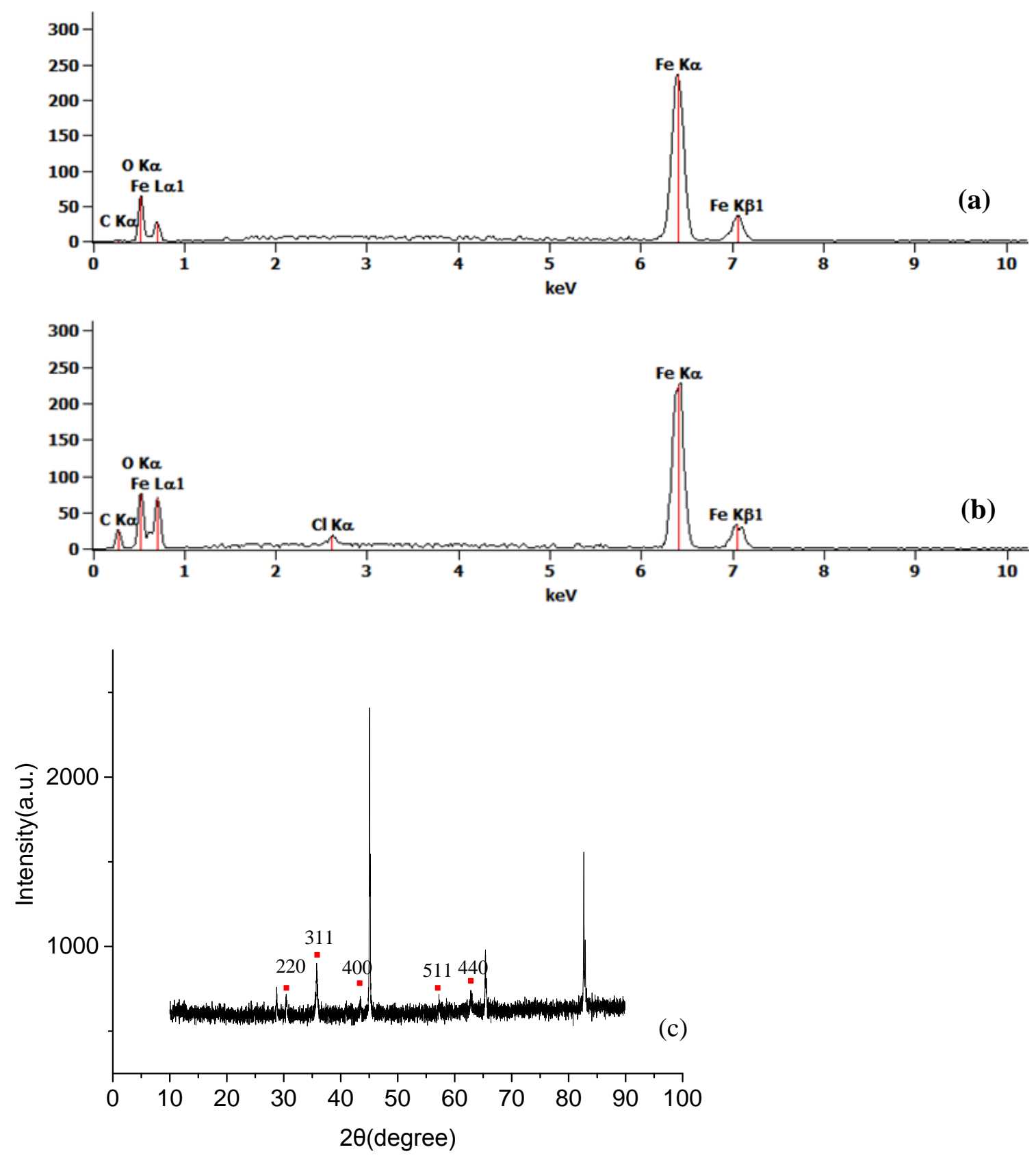

Fig. 3. EDS spectrum of (a) before and (b) after grow nanosheet films for $25 \mathrm{~min}$ in acidic 
solution with introduced oxygen bubbles, (c) XRD patterns of the as-prepared surface, the red box represents the diffraction peaks for $\mathrm{Fe}_{3} \mathrm{O}_{4}$.
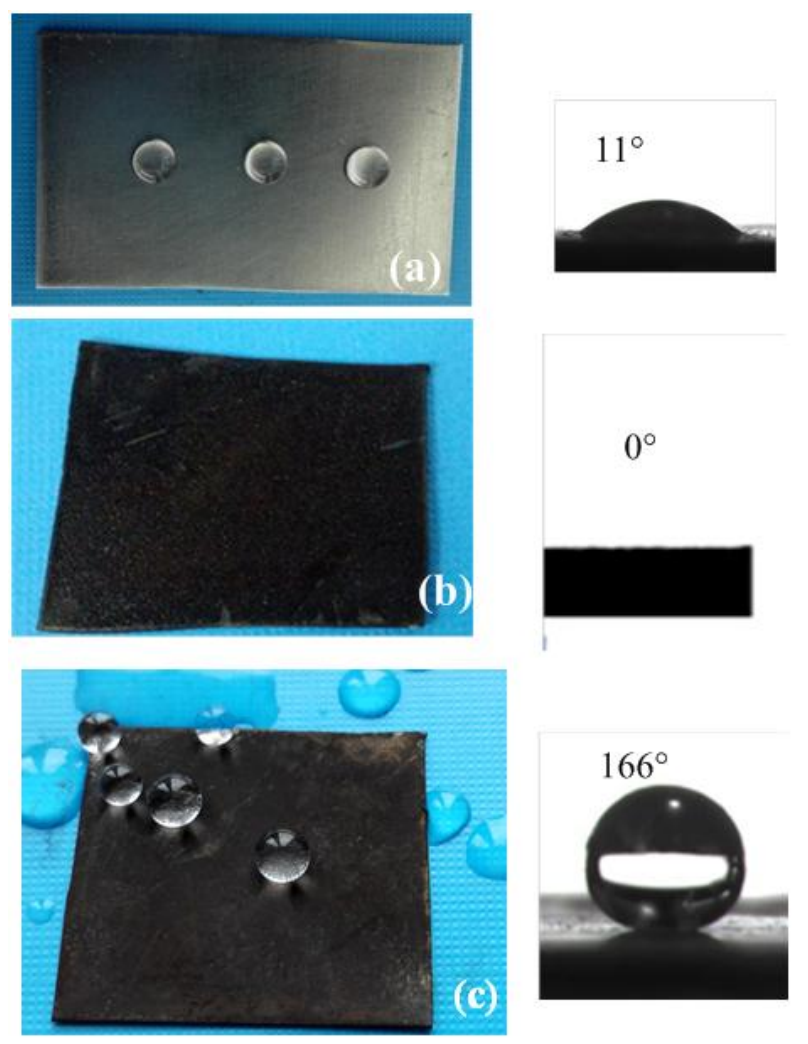

Fig. 4. Optical photo of water droplets on different morphology surface: (a) untreated steel surface, (b) surface of chemical etching and oxidation, and (c) superhydrophobic steel surface. 



Fig. 5. Snapshot photographs of a $10 \mu \mathrm{L}$ water droplet rolling off of the resultant superhydrophobic surface (30 min) (a) $0.5 \mathrm{~s}$, (b) $1 \mathrm{~s}$, (c) $1.5 \mathrm{~s}$, and (d) $2 \mathrm{~s}$. 




Fig. 6. Relationship between the water $\mathrm{CA}$ of the as-prepared steel foil and the reaction time in $70^{\circ} \mathrm{C}$ acidic solution under $\mathrm{O}_{2}$ rich environment. Samples have been modified by fluorinated silane after chemical etching and oxidation. 


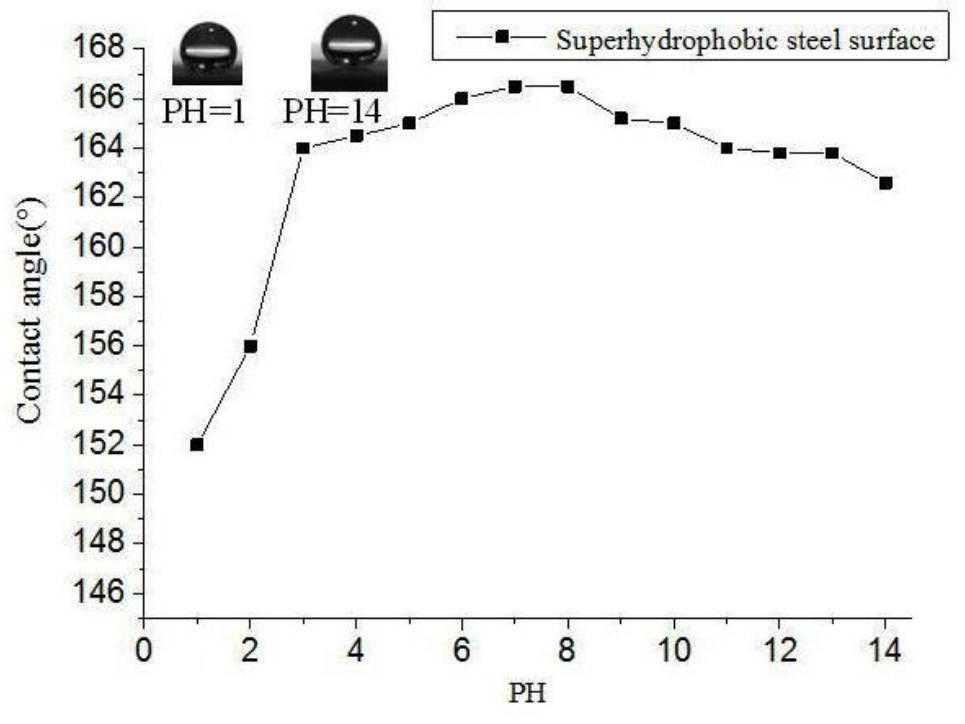

Fig .7. Relationship between the water CA of the as-prepared superhydrophobic steel surfaces and $\mathrm{pH}$ value. 


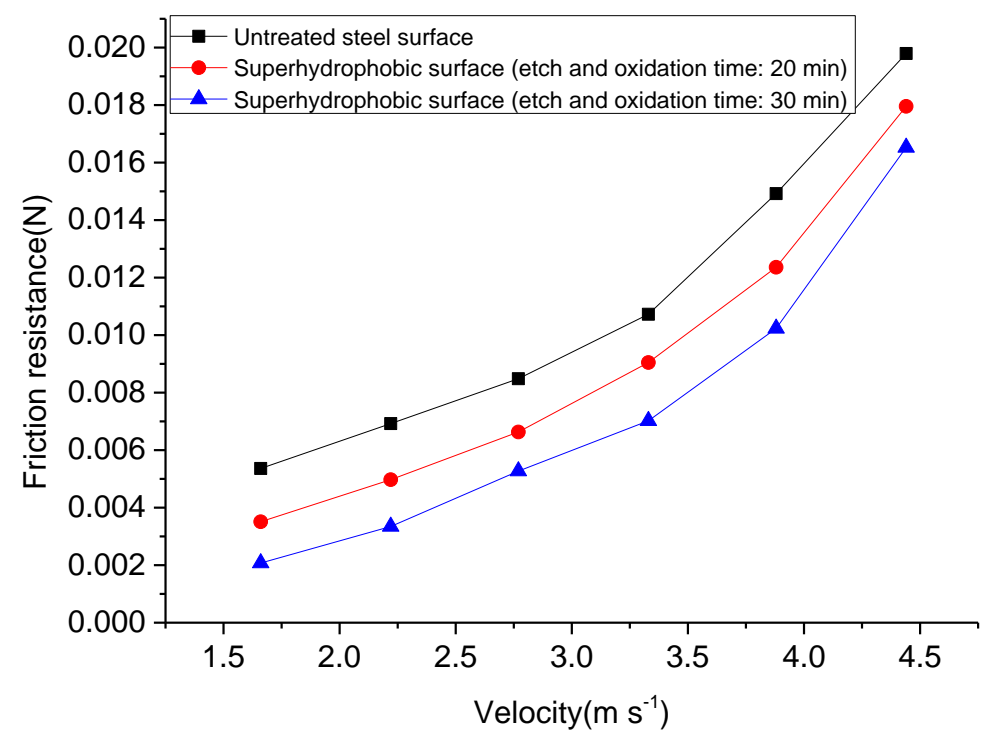

Fig. 8. Friction drag versus the velocity of the water flowing over surfaces 


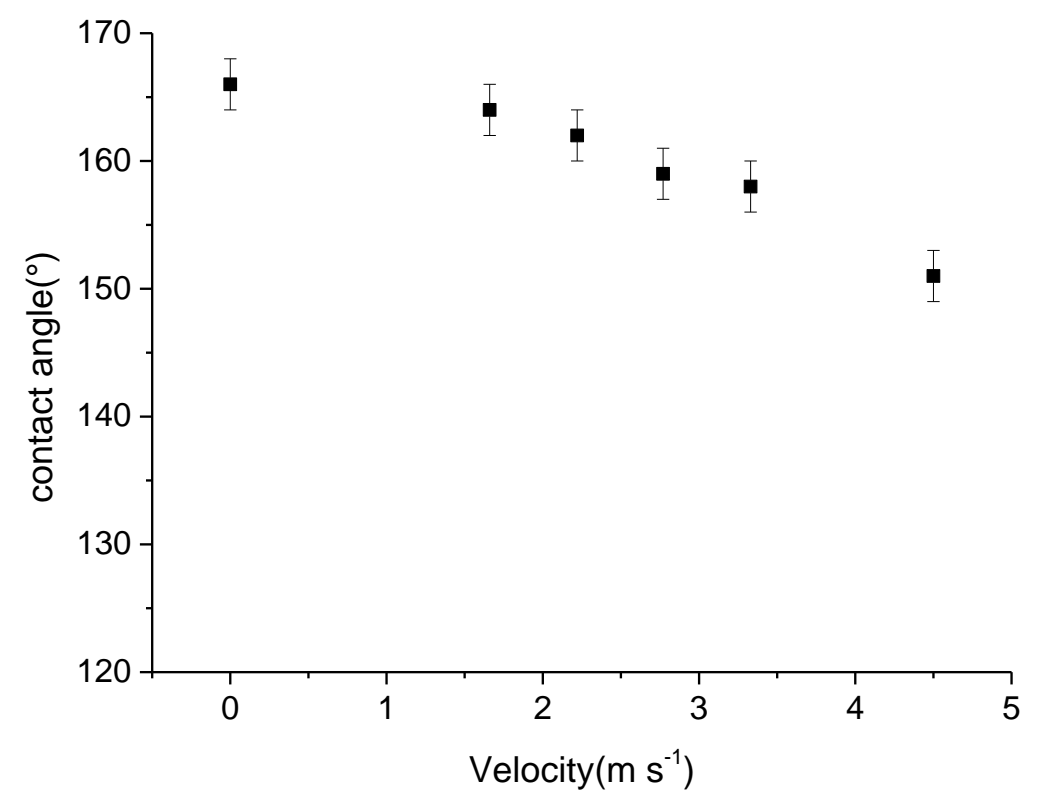

Fig. 9 Graph showing CA measured after flushing water with different flow velocity on the superhydrophobic steel surface. 


\section{Graphical abstract}

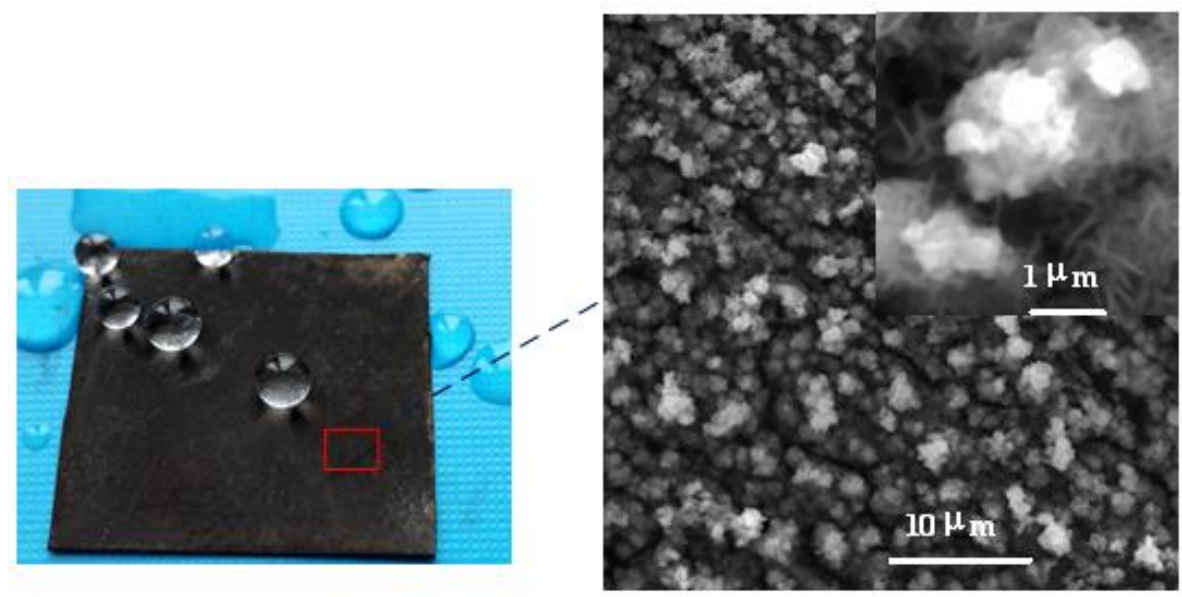

Superhydrophobic surface with highly similar micro-and nanostructures of lotus leaf on steel foil 